\title{
Impact of end of lease contracts' option on joint pricing and inventory decisions of remanufacturable leased products
}

\author{
M. Rabbani ${ }^{\mathbf{a}^{*}}$, S. Keyhanian ${ }^{\mathrm{b}}$, Mansure Hasannia ${ }^{\mathrm{a}}$, Marzieh Eskandari ${ }^{\mathrm{a}}$, Moeen Sammak Jalali ${ }^{\mathrm{c}}$
}

${ }^{a}$ School of Industrial Engineering, College of Engineering, University of Tehran, Iran

${ }^{b}$ Faculty of Mathematics and Natural Sciences, University of Groningen, Groningen, the Netherlands

${ }^{c}$ Department of Industrial Engineering \& Management Systems, Amirkabir University of Technology - Tehran Polytechnic, Iran

\section{H R O N I C L E}

\section{Article history:}

Received July 222015

Received in Revised Format

Septmber17 2015

Accepted November 82015

Available online

November 92015

Keywords:

Leasing

Pricing

End options

Mathematical Model

Remanufacturing

\begin{abstract}
A B S T R A C T
Leasing currently plays an important role for the global economy. The equipment leasing earning acquired through leasing rather than cash or credit, has reached a dominant level. With this regards, this paper represents a basic mixed-integer non-linear programming model. The study deliberates a firm that leases new products and remanufactured leased merchandises. The proposed study considers the end of lease contract, which contains several options: Return the leased product, return the used product and purchase other remanufactured product and buying the leased product. The primary objective is to maximize the discrepancy between the revenue and the costs of a firm, which leases new products as well as selling remanufactured ones. The product deteriorates with time and the difference between a new and used good is obvious. The product must undergo a remanufacturing procedure before being sold as a remanufactured product.
\end{abstract}

\section{Introduction}

\subsection{Motivation and significance}

Literature survey of this paper indicates that there is a need to dedicate research works to the development of models, methods, and solution approaches for investigating different areas in lease contracts. Therefore, a mathematical model is being represented with the intention of maximizing the difference between revenue and firm's cost. The results of the proposed mathematical model show the superiority of the approach in comparison with other related methods in the literature. 


\subsection{Concepts and literature review}

According to Financial Accounting Standards Boards (FASB), a lease is an agreement conveying the right to use property, plant and equipment (PP\&E) usually for a stated period. Explicitly disqualified are lease agreements intended for discovering or manipulating resources such as oil, minerals, gas, and timber, as well as licensing arrangements for items like motion picture films, manuscripts, plays, patents, and copyrights. Likewise, International Federation of Accountants (IFAC) defines a lease as "an agreement whereby the lessor conveys to the lessee in return for a payment or series of payments the right to use an asset for an agreed period”. IFAC also excludes lease agreements for natural resources and licensing agreements (Jorgensen and Kort, 2002). A lease option gives a renter/potential buyer more flexibility than a lease-purchase agreement, which requires the renter to purchase the property at the end of the rental period. There are specific strategies and procedures to follow in preparing an end lease agreement. At the normal end of a lease, we may have the following options: Return, extend, purchase or trade the leased product. Depending on the details of our particular lease situation, some of these options may be practical for us while others may not. The lease company may also remind us of our option to purchase the leased product and provide us a purchase buyout price.

In a representative lease agreement, the lessor funds to an alternate lessee, the exclusive right to make use of the asset for an arranged period. Henceforth, "the lessee takes the risks and returns from the use of the asset, and the lessor takes the risks and returns from ownership of the asset” (Gavazza, 2010). As in any financial agreement, the risk of default by the lessee is a principal component in the risk of ownership, with the insolvency value of the asset playing a key character if the lessee defaults. The activities composing a remanufacturing process can be divided into disassembly, inspection, sorting, cleaning, reprocessing, reassembly, checking and testing. One of the major issues faced by the firms involved in remanufacturing is taking back used products before the expiration of their expedient life so that some income could be engendered by either reprocessing or remanufacturing (Aras et al., 2011). Different activities of remanufacturing include inspection, cleaning, disassembling, component reprocessing, reassembly and testing (Rajagopalan and Xia, 2012). In this paper, we consider a firm leasing one type of a new product, and selling remanufactured versions of this product. Consequently, we assume that the product is durable and remanufacturable. In recent years, there has been a tendency towards the integrated model of pricing and production planning.

There are several studies focused on joint pricing and inventory planning. For instance, Aras et al. (2010) developed a dynamic programming method for determining the optimal price of remanufactured products. They also considered optimal payment construction for the leased new products in order to maximize the profit function over a finite time horizon. They considered revenue earned by selling remanufactured products as well as leasing new products, manufacturing and remanufacturing costs and shortage, holding and inventory costs that finally gives us the optimal pricing of remanufactured and leased products in each period. Nowadays, new sales channels, provides manufacturers greater accessibility to clients and direct sales. Under such circumstances, it can be mentioned that the demand is influenced by price. Smith et al. (2009) considered a model to minimize the cost associated with making decisions on price, profit maximization over a multi-period production master planning horizon with deterministic demand by focusing on both inventory and capacity constraints that are used in practice in the firms. In the first step, the single-period model with the exact solution was solved and then a multi-period model was considered by dynamic programming approach. This model considers the net present value approach instead of the traditional approach.

In this study, we assume that no backlogging is allowed and orders are delivered instantaneously and initial inventory level is zero. In some surveys in the literature, researchers considered the maintenance policy in leasing and investigated the optimal length of lease period and maintenance policy for leased equipment (see Ruey Huei et al., 2011). It was explained that the elements of lease contracts are length of lease period, rent, new/old equipment, penalty, average time of repairing and maintenance plan for 
repairable products. The maintenance plan is divided into two parts: corrective maintenance (CM) and preventive maintenance (PM). A minimal repair is accompanied once the leased equipment fails with the intention of bringing the equipment back to an operating condition. Furthermore, an imperfect preventive maintenance (PM) was carried out to avoid possible failures when the age of the equipment reaches a specified level called as a control-limit.

Keyhanian and Rabbani (2015) explained a new bi-objective, mixed-integer, non-linear mathematical model that maximized revenue and whole lease turnovers. Pricing models are generally defined in the form of a demand function. Therefore, a joint problem was analyzed to determine the price and production decisions simultaneously. In this model, demand function depends on time, price, inflation, etc. and price depends on production cost, revenue expectations, etc. The MINLP model's objectives are gathered into one by using Minkowsky distance-based $L p$-metrics and solved by generalized reduced gradient (GRG) algorithm. Steeneck and Sarin (2013) provided a detailed review about Reverse Supply Chain (RSC) as well as activities including remanufacturing with the intention of finding a significant gap and directions in this area. They mentioned that only one pricing model had been presented in the literature when the per-unit cost of remanufactured products is a function of the quantity remanufactured. They proposed pricing of new and remanufactured products as well as production planning. Since pricing remanufactured products is a function of production cost, production quantity depends on production demand, and demand depends on price of remanufactured product. The joint and integrated model that considers various aspects is very important. Rajagopalan and Nan Xia (2012) considered revenue management for maximizing expected revenue for new or remanufactured product.

Ray et al. (2005) studied the optimal pricing/trade-in for remanufactured durable goods. They considered three pricing methods:

(1) A uniform price for all customers.

(2) The difference between the prices of new and replacement customers independent of age.

(3) The difference between the prices of new and replacement customers as a function of age.

On the other hand, if the company is capable of increasing the durability of the product or dealing with high durability is prerequisite, repayment information will be used in order to determine the optimal distribution for the age profile of the viability of the rebate that is reduced. Toktay et al. (2000) premeditated the entire process on custom policies, which is expected to be minimal inventory and lost sales costs and the uncertainty concerning the characteristics and invisibility. The study used a closed queuing network model and a heuristic methodology was implemented in order to estimate and control the system. The effects of various system parameters such as information structures, procedural delay, and demand rate and cycle length were investigated.

Aras et al. (2011) studied the lease on the company's new products and a new product, which is remanufactured at the end of the lease period, is available to sell. The company may buy new products from third party suppliers, which would not meet remanufactured products' demand. They examined a single-period problem with respect to various parameters such as willingness to pay and willingness to pay for remanufactured products, leasing new product, product depreciation rate over the lease period, etc., which were studied in complex multi-period multi-dependent and remanufactured products. They considered that manufacturers may choose to produce a new product for the future and generate sales of remanufactured products.

Aras et al. (2008) considered a company with new, durable, and remanufactured products at the end of the leasing period that sells the lease with the intention of determining the optimal pricing strategy for increasing profits. Having considered appropriate balance at the end of the lease (when the number of items is not enough to satisfy the demand for remanufactured products), provides companies with the option to purchase additional third-party. This acquires additional cost and formulating the problem as a profit maximization model of consumer surplus. A key feature of the unit cost of a product, such as 
diagnosis and age takes place in the third part suppliers. Therefore, the key characteristics of such markets tend to buy a remanufactured product, and the new product is more likely to be leased. The results were solved by the simplex search method variables, which also satisfied both restrictions. Jorjensen and Kort (2002) controlled the issue of optimal pricing and inventory replenishment in a series of studies. There were influential factors in the product catalog and stock prices in consumer demands for certain products in retail stores. For some consumer products, a large volume of consumer goods was shown to be purchased more if the stock remains small. In addition to in-store stock at central warehouses, product inventory was displayed. On the other hand, optimal responses were obtained from three series: (1) to decentralize, (2) focused on the demand-related decisions, (3) decentralized decision under demand independent. The demand effects depend on optimal pricing and inventory policy, by setting up a series of analytical results were studied. Tilson et al. (2006) presented a dynamic game modeling to investigate the interactions among various distribution channels including: (1) sales of new products to consumers, (2) lease of new products to both consumers and corporations, and (3) sale of off-lease products to consumers. They studied a manufacturer who sells and leases finitely durable products to both individual and corporate consumers, simultaneously. Both the manufacturer and consumers attempt to maximize their individual discounted profits during the plans. They explained that consumers could be classified into four categories: the ones leased every period, those who purchase the new goods and use them for two periods, those who always purchase used goods, and those who do not wish to contribute in the market. They also calculated the selling price of the new products for individual consumers, and leasing prices to both individual and corporate consumers. In some articles, the authors considered the end options at the end of lease period. Gamba and Rigon (2008) studied previous designs and options of pricing models; an assumption that simply cancels the lease contracts for the purchase of fixed interest rate and proposed a model with stochastic interest rates, which significantly expands the cancellation options with the existence of a penalty. The lease contract is influenced by some sources of uncertainty such as the inflation rate and the depreciation of the vehicle dynamics. These were the results of the previous models used to develop the lease contracts set. Mon et al. (2006) studied the use of baby prams that identified the services provided through the sales and lease check where potential obstacles or changes in the product design and supply chain were handled. Reverse logistics and remanufacturing system with various levels of refurbishment baby pram by retailers make up a product service system. Due to the necessity of customers for baby pram in a period and in the end, it should be sold as secondhand goods. They considered a model where the objective of this study was to gain interest by considering environmental issues. Fees covered the costs of negative cash flow in the beginning of lease plan in the first month. Therefore, potential solutions and other potential bottlenecks in the rental scheme were studied. They explained that higher-income leasing and reconditioning could deliver to normal sales and reduce environmental factors.

Ferrer et al. (2010) investigated some firms producing a new product in the first period and used returned cores to make remanufactured products in future studying periods, with new products to make. With this regards, various prices for new and remanufactured products were selected. Planning horizon of this study described that the optimal policy and product lifecycle for all products and remanufactured could be reached. Based on their observations, the marginal cost of remanufacturing decreases, the value of new products in the first period increases, and the value of new products in the coming period decreased. Finally, the optimal policy was that every company needs a different amounts of time to develop new products and remanufacturing items. Wu (2012) studied a supply chain including an original equipment manufacturer (OEM) with a new product and remanufacturer item, used to retrieve the previously studied ones. This model offered two courses that study different strategies for product design and OEM remanufacturer pricing strategy decisions as a game theory, which was resulted in the balance of various scenarios. Finally, the model could be revealed for some time. OEM remanufacturer recovers production costs as well as costs reduced when the disassembly is high. While facing with the amount disassemblability, OEM design is faced with a strategic dilemma. Considerable body of literature proposed extensions addressing the limitations of these models. By studying the research papers, we have realized that there were several gaps in the literature. The objective of our study is to involve the impact 
of end of the lease contract's option on the joint pricing and inventory decisions of remanufacturableleased products. The vast majority of these studies assume pricing or inventory decisions or integrated pricing and inventory decisions for lease systems.

\section{Problem Definition}

In this study, we consider a firm that leases new and remanufactured leased products. In the developed model, we consider the end of lease contract including several options. For instance, returning our leased product, returning used product and purchasing other remanufactured product, and buying leased product. In the first step, we introduce our basic mixed-integer non-linear programming model. Then, we embark on identifying our options, adding the options to our basic model, and we will finally represent our final model by extending the basic one. In our basic model, the objective is to maximize the difference between revenue and costs of a firm that leases new products and sells remanufactured products. The product is durable but has finite life $(\mathrm{L})$. The product deteriorates with time, and the difference between a new and used good is obvious. The product must undergo a remanufacturing operation before being sold as a remanufactured product. The decision making periods (year) of the system is defined as $t=\{1$, $2 \ldots, T$, where $T$ is the length of the planning horizon. Each decision making period is divided into subintervals (months), where lease payments take place. We should mention that time is measured discretely. We also assume that a lease duration is an integer multiple of the length of the decision making period. Inventory left at period $t$, is denoted by $I_{t}$. We assume that a cost $f(\tilde{p}-p)$ incurs if $p$ and $\tilde{p}$ are prices in two consecutive periods, where $\mathrm{f}(0)=0, \mathrm{f}(\mathrm{x})=\mathrm{u}^{+}$if $\mathrm{x}>0$ and $\mathrm{f}(\mathrm{x})=\mathrm{u}^{-}$if $\mathrm{x}<0$ for some $\mathrm{u}^{+}$, $\mathrm{u}^{-} \geq 0$. These costs, referred to as the menu costs or physical costs, which are associated with activities like "constructing new price lists, printing and distributing new list prices and monthly supplemental price sheets, and notifying suppliers”(Chen \& Hu, 2012). Generally, at the end of a lease contract, customer may have the following options:

(1) Return.

(2) Buy leased product.

(3) Renew (return and lease new product).

(4) Return and buy remanufactured product.

Depending on the details of our particular lease situation, some of those options may be practical for customers while others may not. In this model, we investigate the impact of end of lease contracts' option on joint pricing and inventory decisions of remanufacturable-leased products. The problem is to determine the optimal lease and remanufactured goods price as well as production and remanufacturing quantity for each period of a discrete time and finite planning horizon. In each period, a production and remanufacturing capacity, a variable cost of production and remanufacturing, a fixed cost, and a demand function that returns demand as a function of price are considered. The production capacity, variable cost, fixed cost, holding cost, price, and production capacity are allowed to vary in each period.

\subsection{Assumption}

The whole assumptions are gathered as follows:

(1) It is assumed that all acquired used products cannot be used for remanufacturing.

(2) For a remanufacturing company, there are costs for dismantling, inspection, quality assurance, logistics and overheads, cores (used products) transaction, and remanufacturing.

(3) Revenues from selling remanufactured products and leasing new products are collected.

(4) Costs for manufacturing the new items to be leased and costs for remanufacturing returned items are incurred. The system also incurs the holding cost for the excess on-hand inventory of remanufacturable and new product items. 
(5) In this problem, we have one type customer with deterministic demand functions and one product.

(6) The production and remanufacturing capacity is known and finite in each period.

(7) The initial inventory $\left(I_{0}\right)$ is zero, and the inventories of future periods are variables with lower and upper bound.

(8) The monthly lease payments are consisted of two parts: Financial and Depreciation fee.

(9) The decision-making periods are annual, but leasing payments are monthly. Therefore, the MF will be calculated by $\left(\frac{r}{24}\right)$.

(10) Product's depreciation is calculated by straight-line (SL) method.

(11) The customer will pay first fee (DP $)$ at the time of registration, and the second fee $\left(\mathrm{DP}_{2}\right)$ at the time of delivery.

(12) The duration between registration and delivery is considered negligible.

(13) The duration of lease agreements, N, cannot exceed the life cycle of the product.

(14) Used products can be remanufactured only once.

(15) No backlogging is allowed.

\subsection{Proposed model}

\subsubsection{Basic model}

\section{Parameters and Variables}

$\mathrm{h}_{\mathrm{Nt}}$ : holding cost for new product in period $\mathrm{t}$

$\mathrm{h}_{\mathrm{rt}}$ : holding cost for remanufactured product in period $\mathrm{t}$

$\mathrm{P}_{\mathrm{N}, \mathrm{t}}^{\mathrm{L}}$ : Lease price for leased products in period $\mathrm{t}$

$\mathrm{P}_{\mathrm{t}}^{\mathrm{r}}$ : Remanufactured price in period $\mathrm{t}$

$\mathrm{D}_{\mathrm{t}}^{\mathrm{L}}$ : leasing demand for new product in period $\mathrm{t}$

$\mathrm{D}_{\mathrm{t}}^{\mathrm{r}}$ : Demand for remanufactured product in period $\mathrm{t}$

$\mathrm{VC}_{\mathrm{r}, \mathrm{t}}$ : Variable cost of remanufacturing for unit product in period $\mathrm{t}$

$\mathrm{FC}_{\mathrm{o}, \mathrm{t}}$ : Fixed cost of production in period $\mathrm{t}$

$\mathrm{VC}_{\mathrm{o}, \mathrm{t}}$ : Variable cost of production in period $\mathrm{t}$

$\mathrm{FC}_{\mathrm{r}, \mathrm{t}}$ : Fixed cost of remanufacturing in period $\mathrm{t}$

r: Discount rate

$\mathrm{I}_{\mathrm{t}}^{\mathrm{L}}$ : Inventory level for leased product in period $\mathrm{t}$

$I_{t}^{\min L}$ : Minimum allowable inventory level for leased product in period $t$ 
$\mathrm{I}_{\mathrm{t}}^{\max \mathrm{L}}$ : Maximum allowable inventory level for leased product in period $\mathrm{t}$

$\mathrm{I}_{\mathrm{t}}^{\mathrm{r}}$ : Inventory level for remanufactured product in period $\mathrm{t}$

$I_{t}^{\min r}$ : Minimum allowable inventory level for remanufactured product in period $t$

$\mathrm{I}_{\mathrm{t}}^{\max \mathrm{r}}$ : Maximum allowable inventory level for remanufactured product in period $\mathrm{t}$

$\mathrm{B}_{\mathrm{t}}^{\mathrm{L}}$ : Bargaining for leased products in period $\mathrm{t}$

$\mathrm{B}_{\mathrm{t}}^{\mathrm{r}}$ : Bargaining for remanufactured products in period $\mathrm{t}$

$\mathrm{y}_{\mathrm{t}}^{\mathrm{L}}$ : Number of production new goods in period $\mathrm{t}$

$y_{t}^{r}$ : Number of remanufactured product in period $t$

$\mathrm{L}_{\mathrm{N}, \mathrm{t}}$ : Number of leased products in period $\mathrm{t}$

$\mathrm{r}_{\mathrm{t}}$ : Number of remanufactured sold products in period $\mathrm{t}$

$\mathrm{R}_{\mathrm{t}, \mathrm{t}}$ : The number of items that are leased in period $\mathrm{t}-1, \mathrm{t}-2 \ldots \mathrm{t}-\mathrm{L}$, and are due to return to remanufacturable inventory at the beginning of period $t$.

$\mathrm{C}_{\mathrm{t}}^{\mathrm{L}}$ : Production capacity for new product in period $\mathrm{t}$

$\mathrm{C}_{\mathrm{t}}^{\mathrm{r}}$ : Capacity for remanufacturing product in period $\mathrm{t}$

DP: Down payment of lease contract

$\mathrm{P}_{\mathrm{N}, \mathrm{t}}^{\mathrm{L}}$ : Monthly payment in period t lease

$\mathrm{RV}_{\mathrm{N}, \mathrm{t}}$ : Residual Value in period $\mathrm{t}$

$\mathrm{N}$ : Duration of leas contract $\mathrm{N}=\{1 \ldots \ldots \mathrm{L}\}$

$\mathrm{AC}_{\mathrm{t}}$ : Adjustment cost

$\mathrm{P}(\mathrm{R})$ : Maximum remanufactured price

P(L): Maximum leased price

Cd: Cost of disposal

MSRP t: Manufacturer suggested retail price (MSRP) in period t

$\mathrm{e}^{(\mathrm{L})}$ : Selling price of remained new goods at the end of planning horizon

$\mathrm{e}^{(\mathrm{r})}$ : Selling price of remained remanufactured product at the end of planning horizon

$\mathrm{I}_{\mathrm{T}}^{(\mathrm{r})}$ : Inventory level for remanufactured products in period $\mathrm{T}$ (at the end of planning horizon)

$\mathrm{I}_{\mathrm{T}}^{(\mathrm{L})}$ : Inventory level for leased products in period $\mathrm{T}$ (at the end of planning horizon)

$\mathrm{R}_{\mathrm{t}, \mathrm{t}+\mathrm{i}}$ : The number of leased products that were leased prior to period $\mathrm{t}$, and are scheduled to be returned in period $\mathrm{t}+\mathrm{i}($ for $\mathrm{i}=0,1,2, \ldots ., \mathrm{L}-1)$. 
$\mathrm{R}_{\mathrm{t}, \mathrm{t}}$ : The number of items that are leased in period $\mathrm{t}-1, \mathrm{t}-2 \ldots \mathrm{t}-\mathrm{L}$, and are due to return to remanufacturable inventory at the beginning of period $t$.

$\mathrm{V}$ : The coefficient $\mathrm{R}_{\mathrm{t}, \mathrm{t}}$ that is remanufacturable after testing.

Basic problem

$$
\begin{aligned}
& \max Z=\sum_{n=1}^{N} \sum_{t=1}^{T} L_{N, t} \cdot p l_{N, t}-\sum_{t=1}^{T} v c O_{t} \cdot y l_{t}-f c O_{t}+F l_{N, t} \cdot\left(\frac{P}{A}, \frac{r}{12}, \mathrm{~N}\right)+\mathrm{el} \cdot \mathrm{I}_{3}^{l}+\sum_{t=1}^{T} r_{t} \cdot p r_{t}-h_{t}^{r} \cdot I_{t}^{r}-v c r_{t} \cdot y r_{t} \\
& -\sum_{t=1}^{T} f c r_{t}-e r . I_{3}^{r}-c d .(1-\gamma) \cdot R-u \cdot \sum_{t=1}^{T}\left|p l_{t+1}-p l_{t}\right|
\end{aligned}
$$

subject to

$$
\begin{aligned}
& D_{t}^{r}=M_{t}{ }^{r} \exp \left(\frac{-p_{t}{ }^{r}(\mathrm{~N})}{K_{t}{ }^{r}}\right) \\
& D_{t}{ }^{L}=M_{t}{ }^{L} \exp \left(\frac{-p_{t}{ }^{L}(\mathrm{~N})}{K_{t}{ }^{L}}\right) \\
& \mathrm{I}_{t}{ }^{L}=\max \left\{0, \mathrm{I}_{t-1}{ }^{L}+y_{t}{ }^{L}-\sum_{N=1}^{L} L_{N, t}\right\} \\
& \mathrm{I}_{t}{ }^{r}=\max \left\{0, \mathrm{I}_{t-1}{ }^{r}+y_{t}{ }^{r}-r_{t}\right\} \\
& I_{t \text { min }}^{r} \leq I_{t}^{L} \leq I_{t \text { max }}^{r} \\
& r_{t} \leq \min \left\{D_{t}^{r}, I_{t-1}^{r}+y_{t}^{r}\right\} \\
& L_{N, t} \leq \min \left\{D_{t}^{L}, I_{t-1}+y_{t}^{L}\right\} \\
& \mathrm{P}_{t}^{L}=M S R P_{t}-B_{t}{ }^{L}-D P_{N, t} \\
& \mathrm{y}^{r}{ }_{t}=\gamma R_{t, t} \\
& y_{t}{ }^{r} \leq C_{t}{ }^{r} \\
& y_{t}^{L} \leq C_{t}^{L}
\end{aligned}
$$

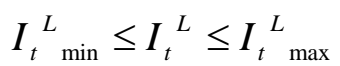

$$
\begin{aligned}
& \mathrm{P}_{t}^{r}=\frac{2 M S R P_{t}}{N}-B_{t}^{r} \\
& F_{N, t}^{L}=\frac{\left(\mathrm{P}_{t}^{L}-R V_{N, t}\right)}{12 N}+\frac{\left(\mathrm{P}_{t}^{L}+R V_{N, t}\right) i}{24} \\
& R V_{N, t}=\alpha P^{L} \\
& P_{t}^{r} \leq P_{t}^{N, L} P_{t}^{N, L} \leq U_{p l} \\
& \left(\mathrm{y}_{t}^{L} \cdot \mathrm{VC}_{L, t}\right)+\left(y_{t}^{r} \cdot \mathrm{VC}_{r, t}\right) \leq \mathrm{B}_{t} \\
& R_{t, t+i}=\sum_{N=i+1}^{L} L_{N, t+i-m} \\
& e^{r} \leq P_{t}^{r} \\
& e^{L} \leq P_{t}^{L} \\
& P_{t}^{N, L}, P_{t}^{r}, e^{r}, e^{L}, y_{t}^{r}, \mathrm{y}_{t}^{L} \geq 0 \\
& N=\{1 \ldots . L\}
\end{aligned}
$$




\subsection{Impact of end of lease contract's option on our model}

Our proposed basic model considers remanufacturing with leasing new products. In this section, we investigate several end of lease contract's options on our model with binary variables. It is mentioned that in each planning horizon, we can choose just one option among our end options.

\subsubsection{The option to return}

When this option is active, our model is the same as the basic model, with the same constraints and customers for leasing just rebounds to returning the used products to us.

$w_{R}^{l}=\left\{\begin{array}{lc}0 & \text { when the end option is to return the used product to the firm } \\ 1 & \text { otherwise }\end{array}\right.$

\subsubsection{The option to buy used product}

In this model, the customers buy their used product of lease contract at the price of $\mathrm{P}_{\mathrm{B}}$ and incurs the income from selling used products with neither remanufacturing nor return. We maintain $\sum_{t=1}^{T} R_{t, t}$ because this is equal to buying demands and change in objective function occurs as follows:

$w_{B}^{l}=\left\{\begin{array}{cc}1 & \text { when the end option is to purchase the used product to the firm with the price of } P_{B} \\ 0 & \text { otherwise }\end{array}\right.$

$\max Z=\sum_{n=1}^{N} \sum_{t=1}^{T} L_{N, t} \cdot p l_{N, t}-\sum_{t=1}^{T} v c O_{t} \cdot y l_{t}-f c O_{t}+F l_{N, t} \cdot\left(\frac{P}{A}, \frac{r}{12}, \mathrm{~N}\right)+\mathrm{el} \cdot \mathrm{I}_{3}^{l}+u \cdot \sum_{t=1}^{T}\left|p l_{t+1}-p l_{t}\right|+\left(1-w_{b}\right) p_{t}^{B} \cdot \sum_{t=1}^{T} R_{t, t}$

\subsubsection{The option to return product and buy remanufactured product}

In this model, the customers return their used products and buy the other remanufactured products. The used products go to remanufacturing process and the customer will be added to the demand of remanufactured products at period $t\left(\mathrm{D}_{\mathrm{t}}^{\prime \mathrm{r}}\right)$. Hence, the added demand is equal to $\mathrm{R}_{\mathrm{t}, \mathrm{t}}$, returned products at the beginning of period $t$, and changing in objective function will be occurred as follows:

$w_{R \& B}^{l}=\left\{\begin{array}{cc}0 & \text { when the end option is to return and purchase } \\ 1 & \text { otherwise }\end{array}\right.$

$\max Z=\sum_{n=1}^{N} \sum_{t=1}^{T} L_{N, t} \cdot p l_{N, t}-\sum_{t=1}^{T} v c O_{t} \cdot y l_{t}-f C O_{t}+F l_{N, t} \cdot\left(\frac{P}{A}, \frac{r}{12}, \mathrm{~N}\right)+\mathrm{el} . \mathrm{I}_{3}^{l}$

$+\left(1-w_{r \& b}\right)\left(\sum_{t=1}^{T} r_{t} \cdot p r_{t}-h_{t}^{r} \cdot I_{t}^{r}-v c r_{t} \cdot y r_{t}-\sum_{t=1}^{T} f c r_{t}-e r \cdot I_{3}^{r}-c d \cdot(1-\gamma) \cdot R_{t, t}\right)-u \cdot \sum_{t=1}^{T}\left|p l_{t+1}-p l_{t}\right|$

\subsection{Final model}

Consequently, we introduce our final model by integrating our basic model with end contract's options using binary variables and constraints. some constraints are common and fixed in several model.

$$
\begin{aligned}
& \max Z=\sum_{n=1}^{N} \sum_{t=1}^{T} L_{N, t} \cdot p l_{N, t}-\sum_{t=1}^{T} v c O_{t} \cdot y l_{t}-f c O_{t}+F l_{N, t} \cdot\left(\frac{P}{A}, \frac{r}{12}, \mathrm{~N}\right)+\mathrm{el} \cdot \mathrm{I}_{3}^{l}+\left(1-w_{b}\right) \cdot p_{t}^{B} \cdot \sum_{t=1}^{T} R_{t, t} \\
& +\left(1-w_{r \& b}\right)\left(\sum_{t=1}^{T} r_{t} \cdot p r_{t}-h_{t}^{r} \cdot I_{t}^{r}-v c r_{t} \cdot y r_{t}-\sum_{t=1}^{T} f c r_{t}-e r \cdot I_{3}^{r}-c d \cdot(1-\gamma) \cdot R_{t, t}\right)-u \cdot \sum_{t=1}^{T}\left|p l_{t+1}-p l_{t}\right|
\end{aligned}
$$




$$
\begin{aligned}
& D_{t}{ }^{r}=M_{t}{ }^{r} \exp \left(\frac{-p_{t}{ }^{r}(\mathrm{~N})}{K_{t}{ }^{r}}\right) \\
& D_{t}{ }^{L}=M_{t}{ }^{L} \exp \left(\frac{-p_{t}{ }^{L}(\mathrm{~N})}{K_{t}{ }^{L}}\right) \\
& \mathrm{I}_{t}{ }^{L}=\max \left\{0, \mathrm{I}_{t-1}{ }^{L}+y_{t}{ }^{L}-\sum_{N=1}^{L} L_{N, t}\right\} \\
& \mathrm{I}_{t}{ }^{r}=\max \left\{0, \mathrm{I}_{t-1}{ }^{r}+y_{t}{ }^{r}-r_{t}\right\} \\
& \mathrm{y}^{r}{ }_{t}=\gamma R_{t, t} \\
& y_{t}{ }^{r} \leq C_{t}{ }^{r} \\
& y_{t}^{L} \leq C_{t}{ }^{L} \\
& I_{t \min }^{{ }^{L}} \leq I_{t}{ }^{L} \leq I_{t \max }{ }^{L} \\
& I_{t \text { min }}^{r} \leq I_{t}^{L} \leq I_{t \text { max }}^{r} \\
& r_{t} \leq \min \left\{D_{t}{ }^{r}, I_{t-1}{ }^{r}+y_{t}{ }^{r}\right\} \\
& L_{N, t} \leq \min \left\{D_{t}^{L}, I_{t-1}+y_{t}^{L}\right\} \\
& \mathrm{P}_{t}^{L}=M S R P_{t}-B_{t}{ }^{L}-D P_{N, t} \\
& \mathrm{P}_{t}^{r}=\frac{2 M S R P_{t}}{N}-B_{t}^{r} \\
& F_{N, t}{ }^{L}=\frac{\left(\mathrm{P}_{t}^{L}-R V_{N, t}\right)}{12 N}+\frac{\left(\mathrm{P}_{t}^{L}+R V_{N, t}\right) i}{24} \\
& R V_{N, t}=\alpha P_{t}^{L} \\
& P_{t}^{r} \leq P_{t}^{N, L} P_{t}^{N, L} \leq U_{p l} \\
& \left(\mathrm{y}_{t}^{L} \cdot \mathrm{VC}_{L, t}\right)+\left(y_{t}^{r} \cdot \mathrm{VC}_{r, t}\right) \leq \mathrm{B}_{t} \\
& R_{t, t+i}=\sum_{N=i+1}^{L} L_{N, t+i-m} \\
& e^{r} \leq P_{t}^{r} \\
& e^{L} \leq P_{t}^{L} \\
& P_{t}^{N, L}, P_{t}^{r}, e^{r}, e^{L}, y_{t}^{r}, \mathrm{y}_{t}^{L} \geq 0 \\
& N=\{1 \ldots . . L\}
\end{aligned}
$$

The objective function maximizes the difference between revenue from selling remanufacturing used product and leasing new ones and different costs of a firm such as remanufacturing costs, disposal cost after testing the used product, fixed and variable costs etc. Eq. (21) demonstrates the remanufacturing demand function in period $t$ that is an exponential function. Eq. (22) demonstrates the leasing demand function in period $t$ that is an exponential function. Third statement represents the inventory level of new products. Eq. (24) indicates the inventory level of remanufactured products. Eq. (25) shows the percentage of used products that receive from previous periods and are remanufacturable after testing process. Eq. (26) and Eq. (27) display the production capacity limitation of new and remanufacturing products. Eq. (28) and Eq. (29) represent upper and lower limits of remanufactured and new products inventory. Eq. (30) is the constraint of selling remanufactured products that is minimum value between demand and available remanufactured product. Eq. (31) is the constraint of leasing new products that is minimum value between demand and available new products at variable lease duration. Eq. (32) is the equation of determining the leasing price of new product. Eq.t (33) is the equation of determining the 
remanufactured product-selling price. Eq. (34) is monthly lease payments that include depreciation fee and financial fee. Eq. (35) illustrate residual value that is the percentage of leasing price. Eq. (36) demonstrates adjustment cost related to changing price from one period to another period. Eq. (37) and Eq. (38) keep remanufactured and new product price between specific maximum and minimum limits that the price of remanufactured product should be less than new product price. Eq. (39) is the budget limitation of variable costs of remanufacturing and production. Eq. (40) is the number of leased product that were leased prior to period $t$ and are scheduled to be returned in period $t+i$. Eq. (41) and Eq. (42) are the limitation of remanufactured and new product selling price at the end of planning horizon. Eq.t (41) show nonnegative and integer variables. Our constraints are binary and in some situations are active.

\section{Methodology}

The model has been solved with General Algebraic Modeling System (GAMS) for two little and medium sizes and for three and five periods. Then, a metaheuristics genetic algorithms (GA) has been also applied for large-scale problems. The pricing strategy in remanufacturable products was studied with game theory (Wu, 2012). Hence, the problem has been solved with Meta heuristics genetic algorithms (GA).

\section{Numerical Results}

The proposed model has been solved by General Algebraic Modeling System (GAMS) for different numerical examples in three sizes and the model is a mixed-integer non-linear programming (MINLP) when $T=3$ periods. Table 1 demonstrates the parameters used for the proposed study.

Table 1

Assumption for holding cost and fixed cost of new and remanufactured products

\begin{tabular}{ccccccc}
\hline $\mathrm{t}$ & $\mathrm{hn}(\mathrm{t})$ & $\mathrm{hr}(\mathrm{t})$ & $\mathrm{vco}(\mathrm{t})$ & $\mathrm{fco}(\mathrm{t})$ & $\mathrm{vcr}(\mathrm{t})$ & $\mathrm{fcr}(\mathrm{t})$ \\
\hline 1 & 40 & 170 & 30 & 200 & 10 & 100 \\
2 & 75 & 210 & 10 & 250 & 5 & 50 \\
3 & 20 & 100 & 20 & 300 & 15 & 120 \\
\hline
\end{tabular}

\section{Table 2}

parameters of examples with 3 periods $(\mathrm{T}=3)$

\begin{tabular}{cccccccc}
\hline Imaxl & 3000 & $\mathrm{Br}$ & 4 & $\mathrm{Upl}$ & 4000 & $\mathrm{Ml}$ & 2500 \\
iminl & 10 & $\mathrm{Cl}$ & 2500 & $\mathrm{~cd}$ & 780 & $\mathrm{Kr}$ & 2.5 \\
imaxr & 3000 & $\mathrm{Cr}$ & 2500 & landa & 0.9 & $\mathrm{Kl}$ & 0.5 \\
iminr & 5 & $\mathrm{Dp}$ & 20 & $\mathrm{j}$ & 0.25 & $\mathrm{~B}$ & $2 \times 10^{\wedge} 10$ \\
$\mathrm{Bl}$ & 10 & $\mathrm{U}$ & 30 & $\mathrm{Mr}$ & 1500 & & \\
\hline
\end{tabular}

The results of GAMS software's BARON solver for problem in small sizes are given in Table 3 as follows:

Table 3

The resuls of the optimal solution

\begin{tabular}{cccc}
\hline & \multicolumn{3}{c}{$\mathrm{n}$} \\
\hline $\mathrm{t}$ & 1 & 2 & 3 \\
\hline 1 & 681.09 & 1969.418 & 1686.696 \\
2 & 681.09 & 1969.418 & 1686.696 \\
3 & 681.09 & 1969.418 & 1686.696 \\
\hline
\end{tabular}




\section{Table 4}

The results of MSRP

\begin{tabular}{cccc}
\hline$t$ & $\mathrm{vl}$ & $\mathrm{MSRP}$ & $\mathrm{Il}$ \\
\hline 1 & 10 & 711.09 & 10 \\
2 & 1256 & 1999.418 & 125.697 \\
3 & 2337.842 & 1716.696 & 2463.539 \\
\hline
\end{tabular}

\section{Table 5}

The results of $\mathrm{Fl}(\mathrm{n}, \mathrm{t})$

\begin{tabular}{cccc}
\hline Fl(n,t) & 1 & 2 & 3 \\
\hline 1 & 14.686 & 42.466 & 36.369 \\
2 & 14.615 & 42.26 & 36.194 \\
3 & 14.544 & 42.055 & 36.018 \\
\hline
\end{tabular}

The results show that $\mathrm{Z}=1391846.166$, el=681.09 and in this problem the buy option after leasing in three periods are suitable. We have investigated the effects of changing in $\mathrm{kr}$ and $\mathrm{kl}$ in choosed option when $\mathrm{Ml}=2500$ and $\mathrm{Mr}=1500$. For our model dut to binary variables, firs we have one option (wb) and by increasing $\mathrm{kl}$ and $\mathrm{kr}$, the option by model was changed to return and buy (wrb).

Table 6

The results of different options

\begin{tabular}{ccccccccccccccc}
\hline $\mathrm{Kr}$ & $\mathrm{Kl}$ & option & $\mathrm{Kr}$ & $\mathrm{Kl}$ & option & $\mathrm{Kr}$ & $\mathrm{Kl}$ & option & $\mathrm{Kr}$ & $\mathrm{Kl}$ & option & $\mathrm{Kr}$ & $\mathrm{Kl}$ & option \\
\hline 0.5 & 0.5 & Wb & 1 & 0.5 & Wb & 1.5 & 0.5 & Wrb & 2 & 0.5 & Wrb & 2.5 & 0.5 & Wrb \\
0.5 & 1.5 & Wb & 1 & 1.5 & Wb & 1.5 & 1.5 & Wrb & 2 & 1.5 & Wrb & 2.5 & 1.5 & Wrb \\
0.5 & 2.5 & Wb & 1 & 2.5 & Wb & 1.5 & 2.5 & Wrb & 2 & 2.5 & Wrb & 2.5 & 2.5 & Wrb \\
\hline
\end{tabular}

After the problem was investigated for three periods, we have studied the model for five periods using some medium sized problems solved in GAMS software's the parameters and the results are represented in Table 7 as follows,

\section{Table 7}

$\mathrm{T}=5$ assumption for holding cost and fixed cost for new and remanufactured products in three periods

\begin{tabular}{|c|c|c|c|c|c|c|}
\hline $\mathrm{t}$ & $\mathrm{hn}(\mathrm{t})$ & $\mathrm{hr}(\mathrm{t})$ & $\mathrm{vco}(\mathrm{t})$ & fco $(t)$ & $\operatorname{vcr}(\mathrm{t})$ & $\mathrm{fcr}(\mathrm{t})$ \\
\hline 1 & 40 & 170 & 30 & 200 & 10 & 100 \\
\hline 2 & 75 & 210 & 10 & 250 & 5 & 50 \\
\hline 3 & 20 & 100 & 20 & 300 & 15 & 120 \\
\hline 4 & 50 & 150 & 50 & 100 & 25 & 150 \\
\hline 5 & 100 & 80 & 20 & 120 & 12 & 80 \\
\hline
\end{tabular}

\section{Table 8}

Parameters of examples with five periods

\begin{tabular}{ccccccccc}
\hline Imaxl & 3000 & $\mathrm{Br}$ & 4 & $\mathrm{Upl}$ & 4000 & $\mathrm{Ml}$ & 2500 \\
iminl & 10 & $\mathrm{Cl}$ & 2500 & $\mathrm{~cd}$ & 780 & $\mathrm{Kr}$ & 2.5 \\
imaxr & 3000 & $\mathrm{Cr}$ & 2500 & landa & 0.9 & $\mathrm{Kl}$ & 0.5 \\
iminr & 5 & $\mathrm{Dp}$ & 20 & $\mathrm{j}$ & 0.25 & $\mathrm{~B}$ & $2 \times 10^{\wedge} 10$ \\
$\mathrm{Bl}$ & 10 & $\mathrm{U}$ & 30 & $\mathrm{Mr}$ & 1500 & & \\
\hline
\end{tabular}

As we can see from the results of Table 9, due to the presence of adjustment cost, cost of changing in leasing prices from one period to another one, fluctuations in leasing prices is very small.

\section{Table 9}

Solution results: examples for five periods

\begin{tabular}{cccc}
\hline $\mathrm{t}$ & $\mathrm{Pl}$ & $\mathrm{Pr}$ & $\mathrm{Il}$ \\
\hline 1 & 0.758 & 22.5 & 10 \\
2 & 0.758 & 22.5 & 10 \\
3 & 0.758 & 17.5 & 10 \\
4 & 0.758 & 22.5 & 10 \\
5 & 0.758 & 17.5 & 10 \\
\hline
\end{tabular}


Table 10

The results of MSRP

\begin{tabular}{cccc}
\hline $\mathrm{t}$ & $\mathrm{Fl}$ & MSRP & Dr \\
\hline 1 & 0.057 & 30.758 & 0.185 \\
2 & 0.057 & 30 & 0.185 \\
3 & 0.057 & 30 & 1.368 \\
4 & 0.056 & 30 & 0.185 \\
5 & 0.056 & 30 & 1.368 \\
\hline
\end{tabular}

As we can also see from the results of Table 10, due to presence of adjustment cost, cost of changing in leasing prices from one period to another one, fluctuations in leasing prices is very small.

Table 11

The results

\begin{tabular}{|c|c|c|c|c|c|c|c|c|c|}
\hline $\mathrm{Dl}$ & & 1 & & 2 & & 3 & 4 & & 5 \\
\hline 1 & & 1846.15 & & 2500 & & 2500 & 2500 & & 2500 \\
\hline 2 & & 1846.15 & & 2500 & & 2500 & 2500 & & 2500 \\
\hline 3 & & 1846.15 & & 2500 & & 2500 & 2500 & & 2500 \\
\hline 4 & & 1846.15 & & 2500 & & 2500 & 2500 & & 2500 \\
\hline 5 & & 1846.15 & & 2500 & & 2500 & 2500 & & 2500 \\
\hline $\mathrm{Kr}$ & $\mathrm{Kl}$ & $\mathrm{Mr}$ & $\mathrm{Ml}$ & Landa & $\mathrm{Z}$ & Option & Landa & $\mathrm{Z}$ & Option \\
\hline 1.5 & 3.5 & 3500 & 1500 & 0.9 & 1391866 & $\mathrm{~Wb}$ & 0.2 & $10^{\wedge} 16$ & Wrb \\
\hline 1.5 & 3.5 & 3500 & 1500 & 0.1 & 1391866 & $\mathrm{~Wb}$ & 0.4 & $10^{\wedge} 16$ & Wrb \\
\hline 3.5 & 1.5 & 1500 & 3500 & 0.9 & 4043.52 & $\mathrm{~Wb}$ & 0.45 & $10^{\wedge} 16$ & Wrb \\
\hline 3.5 & 1.5 & 2500 & 2500 & 0.9 & 1391866 & $\mathrm{~Wb}$ & 0.48 & $10^{\wedge} 16$ & Wrb \\
\hline 2 & 2.5 & 1000 & 4000 & 0.9 & 1391866 & $\mathrm{~Wb}$ & & & \\
\hline 2.5 & 0.5 & 1500 & 1000 & 0.9 & 1391866 & $\mathrm{~Wb}$ & & & \\
\hline
\end{tabular}

The results for five periods yield an objective function of $\mathrm{Z}=8082.977$ and the buy option is selected. We plot in prices with increasing the adjustment cost (u) and present fluctuation in prices with increasing $t$.

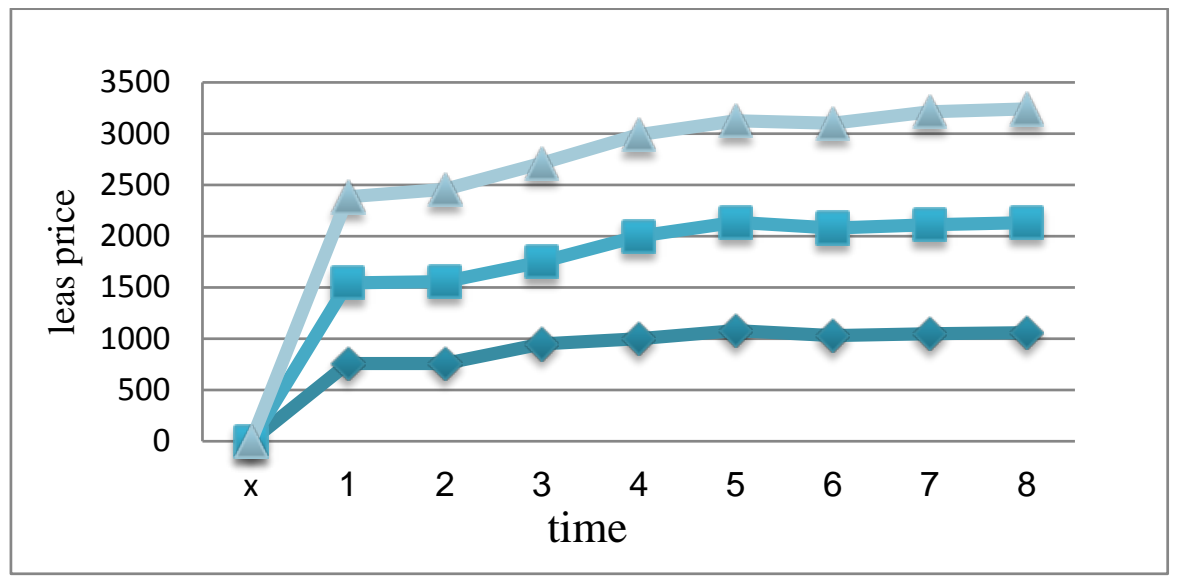

Fig. 1 Output of the model for five periods

\section{Conclusion}

In this paper has proposed a method to determine the end options at the end of lease periods for profit maximization. The primary objective was to maximize the difference between revenue, costs of a firm leasing new products, and selling remanufactured products, defined disposal cost, and adjustment cost in objective function. Due to the growth of leasing options on many durable products, we have considered leasing new products and selling remanufactured products for the proposed model. We have considered the end of lease contract that consists of several options: Return leased product and lease a new one or buying used product. The model has been solved for three little, medium, large sizes. The model has been run with GAMS solver in three and five periods and then it was investigated with genetic algorithms. 
The results have shown that if the disposal cost, coefficient of demand function for new and remanufactured products are changed the results for end of options are altered.

\section{References}

Aras, N., Gullu, R., \& Yurulmez, S. (2008). Optimal pricing for a firm that leases new products and sells remanufactured ones. POMS 19th Annual Conference, La Jolla, 1-36.

Aras, N., Güllü, R., \& Yürülmez, S. (2011). Optimal inventory and pricing policies for remanufacturable leased products. International Journal of Production Economics, 133(1), 262-271.

Chen, X., \& Hu, P. (2012). Joint pricing and inventory management with deterministic demand and costly price adjustment. Operations Research Letters, 40(5), 385-389.

Ferrer, G., \& Swaminathan, J. M. (2010). Managing new and differentiated remanufactured products. European Journal of Operational Research, 203(2), 370-379.

Gavazza, A. (2010). Asset liquidity and financial contracts: Evidence from aircraft leases. Journal of financial Economics, 95(1), 62-84.

Gamba, A., \& Rigon, R. (2008). The value of embedded real options: Evidence from consumer automobile lease contracts-A note. Finance Research Letters,5(4), 213-220.

Jørgensen, S., \& Kort, P. M. (2002). Optimal pricing and inventory policies: Centralized and decentralized decision making. European Journal of Operational Research, 138(3), 578-600.

Keyhanian, S., \& Rabbani, M. (2015). Revenue and turn-over based joint pricing and production planning for an integrated financial lease-sales system: a new mathematical model. International Journal of Operational Research,22(3), 310-341.

Liang, Y., Pokharel, S., \& Lim, G. H. (2009). Pricing used products for remanufacturing. European Journal of Operational Research, 193(2), 390-395.

Mont, O., Dalhammar, C., \& Jacobsson, N. (2006). A new business model for baby prams based on leasing and product remanufacturing. Journal of Cleaner Production, 14(17), 1509-1518.

Gallo, M., Romano, E., \& Santillo, L. C. (2012). A Perspective on Remanufacturing Business: Issues and Opportunities. International Trade from Economic and Policy Perspective, 209.

Smith, N. R., Limón Robles, J., \& Cárdenas-Barrón, L. E. (2009). Optimal pricing and production master planning in a multiperiod horizon considering capacity and inventory constraints. Mathematical Problems in Engineering,2009.

Rajagopalan, S., \& Xia, N. (2012). Product variety, pricing and differentiation in a supply chain. European Journal of Operational Research, 217(1), 84-93.

Ray, S., Boyaci, T., \& Aras, N. (2005). Optimal prices and trade-in rebates for durable, remanufacturable products. Manufacturing \& Service Operations Management, 7(3), 208-228.

Yeh, R. H., Chang, W. L., \& Lo, H. C. (2011). Optimal length of lease period and maintenance policy for leased equipment with a control-limit on age.Mathematical and Computer modelling, 54(9), 20142019.

Steeneck, D. W., \& Sarin, S. C. (2013). Pricing and production planning for reverse supply chain: a review. International Journal of Production Research,51(23-24), 6972-6989.

Tilson, V., Wang, Y., \& Yang, W. (2009). Channel strategies for durable goods: coexistence of selling and leasing to individual and corporate consumers.Production and Operations Management, 18(4), 402-410.

Toktay, L. B., Wein, L. M., \& Zenios, S. A. (2000). Inventory management of remanufacturable products. Management science, 46(11), 1412-1426.

Trigeorgis, L. (1996). Evaluating leases with complex operating options.European Journal of Operational Research, 91(2), 315-329.

Wu, C. H. (2012). Product-design and pricing strategies with remanufacturing.European Journal of Operational Research, 222(2), 204-215. 